\title{
Conclusions and Suggestions for Improving European Education Policies
}

\begin{abstract}
In the concluding chapter, we draw together the main arguments and results of the research, highlighting the differences and similarities between the education policy documents produced by the European Union and the Council of Europe. We also provide suggestions for improving future education policies to better encompass the concerns about the lack of dialogue in a diversified but also polarized Europe. Education policy documents dealing with intercultural dialogue act as important guidelines for tackling racism, chauvinism, xenophobia, homophobia, and other forms of prejudice in Europe. As policies function as 'actants' that create webs of meanings and action, it is crucial that policy documents are conceptually well formulated and clear and reflect today's societies. Lastly, we suggest new a conceptual means-cultural literacyto enhance and implement intercultural dialogue in education.
\end{abstract}

Keywords Policy recommendation • European education policy • Cultural literacy $\bullet$ Dialogue $\bullet$ Empathy

Our analysis of their education policy documents indicates how the Council of Europe and the European Union have continually engaged with enhancing intercultural dialogue in the field of education. The ethos of promoting cultural interaction and mutual respect between people with different national, religious, ethnic, cultural, and linguistic backgrounds 
was embedded in these actors' efforts even before the concept of intercultural dialogue was introduced and established in their policies. The implicit presence of the idea of intercultural dialogue became an explicit goal in their policy discourses during the 2000s, particularly after 2008, when the Council of Europe published its White Paper on Intercultural Dialogue. As our contextual exploration of intercultural dialogue in the introductory chapter highlights, the White Paper contributed to a broader political and scholarly debate on diversity policies in pluricultural and super-diverse Europe. This debate led to the transformation of diversity policies-at least at the discursive and rhetorical levels. Instead of multiculturalism, policy language started to emphasize interculturalism and intercultural dialogue as a practice or process of implementing policy aims. As we noted in the introductory chapter, it is difficult to draw strict distinctions between multiculturalism and interculturalism, as the policy goals and conceptual language are discursively fluid.

In the second chapter, we discussed the emergence and adaption of the concept of intercultural dialogue in the policy discourses deployed by the European Union and the Council of Europe in their education documents. These discourses have developed in close interaction-though the European Union's policy language has often followed the conceptual and thematic formulations of the Council of Europe with a short delay. Our analysis indicated that the Council of Europe and the European Union share a similar understanding of intercultural dialogue-but the frameworks in which they promote it differ. Both actors seek to advance intercultural dialogue as a means of inclusion, cooperation, and mutual (cultural) understanding. In addition to these social emphases, the European Union's stance on intercultural dialogue reflects its interests in promoting political integration in the Union, as well as in economic development and employment in its member states.

Our methodological and theoretical approach to the European education policy documents stemmed from the constructivist perspective on concepts and their capacity to bring about action. The conceptual analysis of the documents indicated how the idea of intercultural dialogue gets its meaning through and in relation to other concepts and terms, such as culture, cultural heritage, identity, diversity, values, inclusion, integration, tolerance, multiculturalism, and multilingualism. These concepts and terms form a discursive ethos that illustrates what areas of life and sectors of societies intercultural dialogue is expected to engage in and impact on. Our analysis demonstrated how these concepts and terms often emerge in 
the policy documents as closely interrelated both semantically (commonly used in descriptions or definitions of each other) and textually (commonly used in the same sentences or paragraphs). We argue that these conceptual densities tell us much more about the discursive meanings of intercultural dialogue than its explicit (and often superficial or lacking) definitions in the policy documents. The concepts and terms often included in these densities - such as multilingualism, migration, cultural exchange, living together, and lifelong learning-underline the more general interest behind the diversity policies of these two actors: to increase the inclusiveness of a multicultural European society.

In the European education policy documents, ideas and practices of intercultural dialogue were addressed to promote specific policy goals. These goals included improving cooperation and communication between (particularly young) people, increasing the cross-border mobility of people in Europe, and strengthening employment prospects through learning foreign languages and being familiar with different cultures in European countries. Moreover, intercultural dialogue was often related to the skills of interacting with people from migrant backgrounds in multicultural environments. Cultural knowledge of national, regional, and local heritages, as well as familiarity with cultural differences and similarities in Europe, were also commonly introduced in the policy documents as key to intercultural dialogue, enabling an open attitude towards others, respect for diversity, and a better understanding of Europe as a whole (DIALLS 2018, 2019).

Our analysis of the European education policy documents brought out how in them concepts are invested with affective meanings and cultural connotations. The conceptual densities in the documents are particularly charged with affects when several powerful concepts, terms, and expressions are brought together and used to argue for political aims. We developed Ahmed's (2004) theory on the stickiness of affects and applied it to our data by approaching some of its core and often-repeated expressions as sticky concepts. Concepts such as peace, freedom, human rights, equality, and democracy have a special layer of meanings due to their long history in European policy discourse and the emotional connotations with them arising from the political contests in post-war and cold war Europe. Moreover, their affective stickiness impacts on other concepts, terms, and expressions found in conceptual densities in the documents. The stickiness makes the concepts appealing, compelling, and difficult to object to. Using these sticky concepts, it is easy to argue for policy goals such as 
promoting intercultural dialogue. Sticky concepts are extremely effective rhetorical tools and, therefore, commonly used in political discourses (Lähdesmäki 2017).

\section{Policy Recommendations}

Education policy documents dealing with intercultural dialogue have the potential to influence how children, young people, and adults are taught about culture, cultural differences, and cultural similarities. They thus serve as important guidelines for tackling prejudice across Europe, including racism, chauvinism, xenophobia, and homophobia. As policies function as 'actants' that create social and semantic spaces, webs of meanings, and action, it is crucial that policy documents are conceptually well formulated and clear and reflect today's pluricultural societies. Concepts have a performative dimension in policy documents: they participate in shaping and giving meanings to the matter at hand, outlining the community at which the policy is aimed, and transforming political goals into action.

We end our book by providing suggestions for improving future European education policies to better encompass the concerns connected to the lack of dialogue in an increasingly diversified but also polarized Europe. These suggestions stem from our data, but we have also taken into account previous scholarly studies on diversity policies and their recommendations for policy-makers. We utilize the UNESCO Survey on Intercultural Dialogue (2018), and its views on advancing intercultural dialogue and supporting respect for cultural diversity and difference, as a general frame of reference for our policy recommendations.

The survey report recommends that policy-makers "[a]dopt education policies that incorporate intercultural dialogue principles" (UNESCO 2018,39 ) and emphasizes the importance of education at all levels, from primary schools to universities, as a mechanism for supporting intercultural dialogue (UNESCO 2018, 8). Moreover, the report notes the need for "the development of closer ties between education and culture, especially through joint projects" (UNESCO 2018, 36). These views resonate with the recommendations provided by the evaluation report of the European Year of Intercultural Dialogue, celebrated by the European Union in 2008. This report suggests the European Union support crosssectoral cooperation between education, culture, youth services, public services, and active citizenship (ECOTEC 2009, 105). We fully agree with the educational priority of advancing intercultural dialogue and the 
importance of bringing educational and cultural practices together as a joint arena for creativity, learning, inclusion, and exchange of views, experiences, and ideas.

The UNESCO survey identifies several challenges and enabling factors for implementing intercultural dialogue in practice. As our research did not focus on the implementation of education policies, we find it important to summarize these here. The report identifies several core challenges for intercultural dialogue: past and present conflicts and violence within and between communities that hinders bringing different people together and having a respectful and mutual dialogue; the absence of national policy on intercultural dialogue and the limited political will and funding for it; increased migration and the practical pressure it may put on education systems; today's media and particularly social media that can generate and propagate negative stereotypes, prejudices, and hate speech; and deeprooted prejudices and rigid social norms that may prevent people, communities, and societies from opening up to cultural differences (UNESCO $2018,8)$. As the enabling factors of intercultural dialogue, the survey report mentions the following: respecting, tolerant, and accepting environments; citizens' comprehensive understanding of cultural diversity that is supported by quality education, media, and other knowledge dissemination practices; policy frameworks that include clear and specific priorities for advancing intercultural dialogue; and an inclusive approach to processes and policy-making regarding intercultural dialogue to enable deeper engagement and ownership of citizens (UNESCO 2018, 8).

Stemming from these results of the UNESCO Survey on Intercultural Dialogue and relying on recommendations provided by the DIALLS project's first policy brief (DIALLS 2019), we suggest the following improvements to European education policies. These suggestions focus on the definitions and uses of concepts and on rethinking the semantics included in them.

As our book has indicated, intercultural dialogue is a fluid concept that is rarely explicitly defined in European education policy documents. The concept gets a variety of meanings through the discursive and affective contexts in which it is used and in relation to other concepts and terms used in describing policy goals. To avoid conceptual ambiguity and vagueness of policies dealing with intercultural dialogue and to enable their efficient implementation, the meaning of the concept of intercultural dialogue should be clearly defined in the policy documents. Conceptual clarity was a core recommendation emphasized over a decade ago, in the ERICart 
report that surveyed diversity policies in 34 European countries in 2008 . It notes how a clear definition of intercultural dialogue helps avoid potential misinterpretations of policy objectives and makes it easier to evaluate their success (Wiesand et al. 2008, xv).

European education policy documents would benefit from a clearer conceptual and contextual specificity overall. Therefore, the key concepts and terms linked to intercultural dialogue and their social, cultural, and political contexts should be explained. This would make the documents more accessible to audiences who are not familiar with the policy rhetoric of the Council of Europe and the European Union. In turn, this would open up the policies for a broader range of potential end-users and facilitate their implementation. We want to emphasize the need to clearly define three concepts - culture, identity, and diversity - that are commonly used in the policy discourses on intercultural dialogue but which may include a variety of different meanings, even within the same document.

The European education policy documents should clearly indicate whose culture is addressed in them, what features in people's behaviour and habits are viewed as 'cultural', what is the relationship between values and culture, and which values can be perceived as cultural (see Lähdesmäki and Wagener 2015,27). The concept of culture should be grounded in a social constructionist approach. Instead of understanding it as a static and normative entity that can be taught and transmitted to future generations, we recommend approaching culture as a social construction-as a constantly transforming and fluid collective interaction between diverse people (see Otten 2003; Abdallah-Pretceille 2006). Related to this point of view, we recommend that practising intercultural dialogue would not centre around teaching and learning factual knowledge of others' cultures. Teaching and learning 'facts' about different cultures may lead to perceptions of people as stable representatives of their cultural group, whether it be nation, religion, or ethnic origin. This may lead to cultural stereotyping and categorizing that makes it more difficult to perceive people as individuals, and may even engender prejudices (Abdallah-Pretceille 2006; Portera 2008). The ERICart report suggested taking a critical view of cultural canons - established or even listed nationally or internationally important cultural 'facts' and artefacts-and questioning their normative role in education (Wiesand et al. 2008, 146). The creation and transmission of cultural canons construct static cultural understandings of homogeneous communities and maintain the idea of cultural differences between 'us' and 'them' (Maine et al. 2019). The ERICart report 
recommended that education and art institutes shift their focus from traditional and national cultural canons to open processes of creative interaction between people (Wiesand et al. 2008, 146). Openness, cultural hybridity, and learning processes in creative interaction lay a fruitful foundation for intercultural dialogue in today's super-diversified Europe.

Another challenging concept in the European education policy documents is that of identity. The authors of the documents should clearly explain whose and what kind of identity they are addressing. The examined Council of Europe and the European Union documents refer to both individual and collective identities. We recommend approaching both individual and collective identities as plural, multi-layered, processual, and transforming. Moreover, different kinds and formations of identities should be addressed in a non-exclusive manner. Identity and culture are closely connected to diversity and how it is dealt with and given meanings in education policy documents. We recommend that education policies do not limit their approach to diversity to differences in national culture, ethnicity, religion, or language but include (cultural) differences evoked by history, social class, gender, sexual orientation, (dis)ability, indigenousness, and worldviews. The documents we analysed contained very few explicit mentions of these latter differences. Moreover, in the documents, the view of gender was based on static male/female binary. We recommend that the notion of intercultural dialogue should address a broad variety of differences and approach them from an intersectional point of view (Lähdesmäki et al. 2015, 345).

Lähdesmäki and Wagener's (2015) analysis of the White Paper on Intercultural Dialogue showed how the Council of Europe's policy discourse includes hierarchical power positions between those who are expected to lead and facilitate intercultural dialogue and those expected (only) to participate in it. Therefore, we consider it crucial to ask from whose point of view policies and practices on intercultural dialogue are planned. Our analysis indicated that migrants and refugees from nonEuropean countries form a major target group for intercultural dialogue in European education policies. It is important that these policies recognize the power structures between the underprivileged and privileged, such as migrants, refugees, or minorities and majority cultures or inhabitants in receiving countries. Intercultural dialogue may, moreover, create hierarchical structures between different minority communities. As some communities are more commonly explicitly included in the policy discourses on intercultural dialogue, they may be more 'naturally' targeted in the 
implementation of those policies and, thus, have better access to intercultural dialogue than those communities ignored or rarely mentioned in these policies.

European education policy documents commonly use universalizing rhetoric, in terms such as 'equal access' and 'non-discrimination'. Instead of vague idealistic expressions, we recommend identifying the problems of access and discrimination for specific groups and explaining whose access and what kind of discrimination the documents are addressing. This advances the recognition of specific problems and discrimination, making it possible to tackle them more efficiently. We also recommend explicitly acknowledging the problem-based roots of European education policy documents, as they are commonly created as a response to some specific concern or debate.

We recommend paying more attention to the affective connotations and symbolic value of European education policy rhetoric. For example, European education policies commonly include idealistic rhetoric that affectively and effectively appeals to inclusion and integration in Europe, referring to 'us' as a community with shared cultural features, heritage, and/or values. Particularly in the policies of the European Union, the emphasis on the unity of an imagined 'us' may create a symbolic border between those who conform to it and those who do not. The emphasis on 'us' calls for definitions of 'them'. The idea of unity may thus turn into affectively charged antagonism against other continents, economic powers, non-European opponents, migrants, and so on. Similarly, the concept of tolerance is inherent with tensions between otherness and inclusion: the one who tolerates manifests the 'norm' and has the power to decide what kinds of differences are acceptable, while those being tolerated manifest the other (Moore et al. 2011; Brown and Forst 2014). Instead of using implicitly hierarchical expressions and concepts, we recommend emphasizing dialogue in the education policy documents.

\section{Enhancing Intercultural Dialogue Through Cultural Literacy Education}

The DIALLS project has elaborated on the concept of cultural literacy and created a Cultural Literacy Learning Programme as a new means of advancing intercultural dialogue in schools. DIALLS' notion of cultural literacy stems from criticism of teaching knowledge and 'facts' of different 
cultures as a point of departure for understanding cultural differences and being able to encounter people with different cultural backgrounds. The concept of cultural literacy is not a new one but has been discussed in academia since the 1980s. In this early scholarly literature (e.g. Hirsch 1989; Hirsch et al. 1993, 2002), cultural literacy is often narrowly perceived as knowledge of culture gained through the exploration of cultural products, such as literature and art, and learning canonical cultural and historical facts and narratives. This notion conveys cultural literacy as a monologic one-way transmission of cultural knowledge and as something removed everyday life and the constantly transforming reality of pluricultural societies (Maine et al. 2019).

In DIALLS, cultural literacy is reconceptualized as a social practice (see Street 1984) that is inherently dialogic and based on learning and gaining knowledge through emphatic, tolerant, and inclusive interaction with others. It is defined as a process of engaging with cultures, based on an emphatic, tolerant, and inclusive mindset and a co-creation and expression of cultural identities and values. Being culturally literate is defined as an individual's competence and skill to encounter cultural differences and to elaborate on one's own identity in respectful interaction with other people. For DIALLS, being culturally literate means understanding that people may hold differing views but it also presupposes metacognitive awareness of how people's own cultural affiliations influence their responses and feelings towards others (DIALLS 2019; Maine et al. 2019).

Intercultural dialogue as policy needs to be implemented through more concrete tools. European education policy documents rarely explicitly seek to promote intercultural dialogue through learning and gaining knowledge from empathetic interaction with others or through training and strengthening competencies and skills to simultaneously encounter cultural differences and elaborate on one's own identity in respectful social interaction. Even though different forms of literacy, such as media literacy, are addressed in the European education policy documents, literacy as cultural communication, interaction, and empathetic understanding deserves more attention in future policies. Therefore, we recommend that European education policies more clearly emphasize intercultural dialogue instead of dialogue between monolithic cultures and use cultural literacy as a conceptual and practical means to advance this. 


\section{REFERENCES}

Abdallah-Pretceille, M. 2006. Interculturalism as a Paradigm to Think About Diversity. Journal of Intercultural Education 17 (5): 457-483.

Ahmed, S. 2004. The Cultural Politics of Emotion. Edinburgh: Edinburgh University Press.

Brown, W., and R. Forst. 2014. The Power of Tolerance: A Debate. New York: Columbia University Press.

DIALLS. 2018. Cultural Analysis Framework. https://dialls2020.eu/wp-content/uploads/2019/09/resubmitted-cultural-analysis-framework-with-coversheet-.pdf.

- 2019. Developing Education Policies in Europe to Enhance Cultural Literacy. https://dialls2020.eu/wp-content/uploads/2019/04/DIALLSPolicy-Brief-1-Developing-Educational-Policies.pdf.

ECOTEC. 2009. Evaluation of the European Year of Intercultural Dialogue 2008. Final Report. Birmingham: ECOTEC. https://ec.europa.eu/culture/sites/ culture/files/intercultural-dialogue-year-evaluation-2009_en.pdf.

Hirsch, E.D. 1989. A First Dictionary for Cultural Literacy: What Our Children Need to Know. New York: Houghton Mifflin Harcourt.

Hirsch, E.D., J.F. Kett, and J. Trefil. 1993. The Dictionary of Cultural Literacy. What Every American Needs to Know. 2nd ed. New York: Houghton Mifflin Company.

- 2002. The New Dictionary of Cultural Literacy: What Every American Needs to Know. 3rd ed. Boston, New York: Houghton Mifflin Company.

Lähdesmäki, T. 2017. Politics of Affect in the EU Heritage Policy Discourse: An Analysis of Promotional Videos of Sites Awarded with the European Heritage Label. International Journal of Heritage Studies 23 (8): 709-722.

Lähdesmäki, T., and A. Wagener. 2015. Discourses on Governing Diversity in Europe: Critical Analysis of the White Paper on Intercultural Dialogue. International Journal of Intercultural Relations 44: 13-28.

Lähdesmäki, T., P.C.C.A. Heynderickx, A. Wagener, and S.M.F. Dieltjens. 2015. Negations and Negativity as Linguistic Devices in Policy Discourse of Intercultural Cities. Journal of Multicultural Discourses 10 (3): 332-348.

Maine, F., V. Cook, and T. Lähdesmäki. 2019. Reconceptualizing Cultural Literacy as a Dialogic Practice. London Review of Education 17 (3): 382-391.

Moore, H., K. Walker, and C. Alan. 2011. Tolerance: A Concept Analysis. Journal of Theory Construction \& Testing 15 (2): 48-52.

Otten, H. 2003. Intercultural Learning and Diversity in Higher Education. Journal of Studies in International Education 7 (1): 12-26.

Portera, A. 2008. Intercultural Education in Europe: Epistemological and Semantic Aspects. Intercultural Education 19 (6): 481-491. 
Street, B. 1984. Literacy in Theory and Practice. Cambridge: Cambridge University Press.

UNESCO. 2018. UNESCO Survey on Intercultural Dialogue 2017. Analysis of Findings. Paris: UNESCO.

Wiesand, A., I. Heiskanen, R. Mitchell, D. Cliché, M. Fisher, and L. Marsio. 2008. Sharing Diversity. National Approaches to Intercultural Dialogue in Europe. Bonn: European Institute for Comparative Cultural Research.

Open Access This chapter is licensed under the terms of the Creative Commons Attribution 4.0 International License (http://creativecommons.org/licenses/ by $/ 4.0 /$ ), which permits use, sharing, adaptation, distribution and reproduction in any medium or format, as long as you give appropriate credit to the original author(s) and the source, provide a link to the Creative Commons licence and indicate if changes were made.

The images or other third party material in this chapter are included in the chapter's Creative Commons licence, unless indicated otherwise in a credit line to the material. If material is not included in the chapter's Creative Commons licence and your intended use is not permitted by statutory regulation or exceeds the permitted use, you will need to obtain permission directly from the copyright holder.

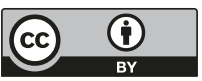

